\title{
Identifying the bottom line after a stock market crash
}

\author{
B.M. Roehner * \\ L.P.T.H.E. University Paris 7
}

\begin{abstract}
In this empirical paper we show that in the months following a crash there is a distinct connection between the fall of stock prices and the increase in the range of interest rates for a sample of bonds. This variable, which is often referred to as the interest rate spread variable, can be considered as a statistical measure for the disparity in lenders' opinions about the future; in other words, it provides an operational definition of the uncertainty faced by economic agents. The observation that there is a strong negative correlation between stock prices and the spread variable relies on the examination of 8 major crashes in the United States between 1857 and 1987. That relationship which has remained valid for one and a half century in spite of important changes in the organization of financial markets can be of interest in the perspective of Monte Carlo simulations of stock markets.
\end{abstract}

\section{September 1999}

Key words Stock market - Crashes - Uncertainty - Interest rate spread - Comparative study

\footnotetext{
* Postal address: LPTHE, University Paris 7, 2 place Jussieu, 75005 Paris, France E-mail: ROEHNER@LPTHE.JUSSIEU.FR
}

FAX: 33144277990 


\section{Stock prices and interest rates}

In this paper we show that in the time interval between crash and recovery there is a clear relationship between price variations and the dispersion of interest rates for bonds of different grades (see below), i.e. what is usually called the interest rate spread. Before explaining this relationship in more detail let us emphasize that it was observed empirically from the mid-nineteenth century to the latest major crash in 1987. This is in strong contrast with so many "regularities" which are dependent upon specific business circumstances. Such is for instance the case of the interest rate itself.

Because of the close connection between stock and bond markets one would expect a strong link between stock prices and interest rates. This is not the case however; there seems to be no permanent relationship between these variables; see in this respect the conclusions of [13] and [18, p.241]. It is true that sometimes a slight decrease in interest rates, by changing the "mood" of the market, suffices to send prices upward. Thus, in the fall of 1998 three successive quarter point decreases of the federal-fund rate (that is to say a global - $0.75 \%$ ) stopped the fall of the prices and brought about a rally. In other circumstances, however, even a huge drop in interest rates is unable to stop the fall of stock prices; an example is provided by the period from January 1930 to May 1931 when the interest rate fell from $6 \%$ to $2 \%$ without any effect on the level of stock prices; similarly in the aftermath of the 1990 crash of the Japanese stock market interest rates went down to almost zero percent without bringing about any recovery.

One should not be surprised by the changing relationship between stock price levels and interest rates. Something similar can be observed in meteorology: sometimes a small fall in temperature is sufficient to produce rain, while in other circumstances a huge fall in temperature will not give any rain. In this case we know that the phenomenon has something to do with the hygrometric degree of the air; in the case of the stock market we do not really know which one of the many other variables plays the crucial role. In the light of such changing patterns the fact that the relationship between stock prices and the spread variable appears to be so robust and so stable in the course of time is worthy of attention.

\section{Interest rate spread and uncertainty}

It is a common saying that "markets dislike and fear uncertainty". In a strong bull market there is little uncertainty; for everybody the word of the day is "full steam ahead". The situation is completely different after a crash. There is uncertainty about the duration of the bear market; some would think that it will be short while others expect a long crisis. In 1990 when the bubble burst on the Tokyo stock market only few people would probably have expected the crisis to last for almost ten years. There is also uncertainty about which sectors will be the first to emerge from the turbulence: banks or investment funds, property funds or technology industry, etc.

As we know the interest rate represents the price a company pays to buy money for the future. The more uncertain the future, the riskier the investment, the higher the interest rate. We will indeed see that during recessions interest rates often (but not always) show an upward trend. In addition, and this is probably even more important, the increased uncertainty produces greater disparity in the rate of different loans. This uncertainty has different sources (i)those who expect a short crisis will be tempted to lend at lower rates than those who fear a protracted recession (ii) the fact that there is no longer any "leading force" in the economy obscures expectations; therefore it becomes more difficult to make a reliable risk assessment for low-quality borrowers (representing the so-called low-grade bonds).

In short, the interest rate spread gives us a means to probe the mood, expectations and forecasts of managers, a means which is probably more reliable than the standard confidence indexes obtained from surveys (in this respect see the last section). 
Although in many econophysical models of the stock market $[3,5,7,9,10,16]$ interest rates do not play a role per se, the fact that uncertainty is greater in the downward phase of the speculative cycle than in the upward phase could be built into the models by adjusting the randomness of the stochastic variables used in Monte Carlo simulations. In contrast, interest rates usually play a determinant role in econometric models. A particularly attractive model of that kind is the Levy-Levy-Solomon model; it describes the stock and bond markets as communicating vessels and how traders switch from one to the other. The book by Oliveira et al. [12, chapter 4] details the assumptions of the model, and, through simulations, explains how it works and to which results it leads.

\section{The data}

Monthly stock price data going back into the 19th century can be found fairly easily; possible sources are $[4,8,17]$. Measuring interest rate spreads is a more difficult matter. To begin with it is not obvious which estimates should be used. The primary source about bond rates is [8]; furthermore a procedure for constructing the spread measure was proposed in [11]. As a matter of fact Mishkin's stimulating paper provided the main incentive for the writing of the present paper. Mishkin proposed to represent the spread by the difference between the one-fourth of the bonds of the lowest grade (i.e. high rates) and the one-fourth of the bonds of the best grade (i.e. low rates). It turns out that even for the midnineteenth century Macaulay's data provided at least three bonds in each of these classes which is fairly sufficient to give acceptable accuracy; for the more recent period 1888-1935 there are as many as 10 bonds in each "quartile". For post-World War II crashes, Macaulay's series can be prolonged by the data in [1]. More detailed comments about how these two measures compare can be found in [11]

\section{Results}

\subsection{Connection between share prices and interest rate spread between crash and recovery}

Fig.1a and $1 \mathrm{~b}$ show the evolution of stock prices (thick solid line), interest rate spread (thick dashed line), and interest rate (thin dashed line) for 8 major crashes. The left-hand vertical scale is the same for all graphs except 1929: this allows a visual comparison of the crashes' severity. The right-hand vertical scales although not identical (which was not possible due to different orders of magnitude) are nevertheless comparable in the sense that the overall range $y_{\max } / y_{\min }$ is the same (except again for 1929); this allows a visual comparison of the increase of the spread. The horizontal scales represent the number of months after the crash; these scales are the same for all graphs (with the exception of 1929); this allows a comparison of the time elapsed between crash and recovery.

It can be seen that the decline in stock prices is mirrored in a similar increase in interest rate spread. As a matter of fact the chronological coincidence between the troughs of the stock prices and the peaks of the spread variable is astonishing. Even for the 1929-1932 episode for which there is a 30-month span between crash and recovery the peak for the spread variable coincides almost to the month with the end of the price fall.

The connection between both variables is confirmed by the correlation coefficients (left-hand correlations in Fig.1): they are all negative and comprised between -0.64 and -0.94 ; note that the smallest correlation (-0.64) corresponds to a relatively small crash with a fall in stock prices of less than $20 \%$.

For 19th century episodes the interest rate changes are more or less in the same direction as those of the spread variable; however the correlations with stock prices (right-hand correlations in Fig.1) are 
substantially lower. For 20th century episodes the picture changes completely: the interest rate no longer moves in the same direction as the spread variable; consequently these correlations become completely random in contrast to the correlations between stock prices and spread variable which remain close to -1 . In the interpretative framework that we developed above we come up with the following picture. After a crash uncertainty, doubts and apprehension begin to spread throughout the market; usually (leaving 1929 apart for the moment) the fall last about 10 months; during that time, uncertainty continues to increase. Then, suddenly, within one month, the trend shifts in the opposite direction: price begin to increase and uncertainty to subside.

One may wonder how the spread variable behaved in the bull phases. First of all one should note that not all the crashes that we examined were preceded by a wild bull market; so we concentrate here on three typical bull markets that occurred in 1904-1907, 1921-1929 and 1985-1987. During these periods the spread variable remained almost unchanged. Similarly during the period 1950-1967 which was marked by a considerable increase in stock prices (without however being followed by a major crash) the spread variable remained at a fairly constant level of $1.5 \%$. In contrast during the period 1968-1979 which was marked by a downward trend in stock prices the spread variable was substantially larger in the range $2.5 \%-3.8 \%$.

A simple look at the charts in Fig.1 confirms what we already know, namely that the crisis of 19291932 was quite exceptional. This is of course obvious in economic terms (unemployment, drop in industrial production, etc.); it is also true from a purely financial perspective. Stock prices plummeted from a level 100 to less than 20, and the spread variable increased from $2.5 \%$ to almost $8 \%$, a three-fold increase. For other episodes (see table 1) the corresponding ratios are all below 1.85. As an illustration of the intensity of the financial crisis one can mention the fact that November and December 1929 saw the failure of 608 banks; the crisis continued in subsequent months to the extent that in March 1933 one third of all American banks had disappeared ([11]).

Table 1 Stock price changes versus increase in interest rate spread

$\begin{array}{ccc}\begin{array}{c}\text { Year } \\ \text { of crash }\end{array} & \begin{array}{c}\text { Stock price } \\ \text { fall } \\ A_{\text {price }}\end{array} & \begin{array}{c}\text { Interest rate spread } \\ \text { increase } \\ A_{\text {spread }}\end{array} \\ & & 1.46 \\ 1857 & 1.63 & 1.32 \\ 1873 & 1.24 & 1.09 \\ 1890 & 1.23 & 1.38 \\ 1893 & 1.34 & 1.82 \\ 1906 & 1.46 & 3.05 \\ 1929 & 6.12 & 1.82 \\ 1937 & 1.89 & 1.25 \\ 1987 & 1.40 & \end{array}$

where:

$$
A_{\text {price }}=\text { peak price } / \text { minimum price }, \quad A_{\text {spread }}=\text { maximum spread } / \text { initial spread }
$$

If we leave 1929 apart the fall/increase ratios of the two variables are almost of the same magnitude; a linear fit gives:

$$
A_{\text {nrice }}=\alpha A_{\text {spread }}+\beta
$$


with: $\alpha=0.63 \pm 0.50, \beta=0.54 \pm 0.13$, the correlation is equal to $r=0.74$ (confidence interval for $r$ to probability 0.95 is 0 . to 0.96 ).

If we include 1929 in the sample the coefficients of the linear fit change completely and become: $\alpha=2.53 \pm 0.67, \beta=-2.11 \pm 0.39$, with a correlation equal to 0.96 (confidence interval to probability 0.95 is 0.74 to 0.99 ). Needless to say the last fit has to be looked upon with cautiousness since it is so much dependent upon the figures of the 1929 crash.

\subsection{Connection between interest spread and market's uncertainty}

In section 3 we interpreted the spread variable as characterizing the uncertainty and lack of confidence existing in the market at a given moment. This interpretation was based on plausible arguments but one would be on firmer ground if it could be supported by some statistical evidence. In this paragraph we provide at least partial proof in that respect by comparing the changes of the spread variable to the consumers' lack of confidence as measured by standard surveys. This is shown in Fig. 2.; it represents the spread variable along with the lack of confidence index in the United States in the period before and after the $1987 \mathrm{crash}$. Changes in the two variables are fairly parallel although the spread variable appears to be much more sensitive and displays larger fluctuations. In the two months before the crash of 19 October 1987 both the uncertainty (measured by the spread variable) and the lack of confidence (estimated through consumer surveys) increased by about 20\%; after the crash both variables increased rapidly; but the after-effects of the crash were short-lived and uncertainty decreased after the beginning of 1988. If consumer confidence data could be found for the period prior to World War II it would of course be interesting to perform a similar comparison for other crashes.

\section{Perspectives for an extension to other speculative markets}

Relationships which have a validity extending over one century are not frequent either in economics or in finance. Yet, if the above observation remains isolated it will be hardly more than a technical feature of interest for stock market professionals. It is tempting to posit that an increase in uncertainty can play a similar role in other speculative markets. Stock markets are certainly special in so far as they are pure speculative markets; in contrast to property or commodities, stocks do not have any other usage for their buyer than to earn dividends. Nevertheless the stock market seems to be in close connection with the property market; historically stock market crashes have often been preceded by a collapse of property prices; see in this respect [6, p.65] and [14, p.76]. One problem with the property market is its long relaxation time. For that reason we consider here another case namely the market for gold, silver and diamonds. As is well known, starting in 1977 huge speculative bubbles developed in these items, which collapsed simultaneously in January 1980. Let us concentrate on the diamond market since the gold market has already been closely investigated particularly by A. Johansen and D. Sornette. In Fig.3 we represented the price of diamonds along with the consumer lack of confidence index that we already used above. Two observations can be made (i) There is a huge increase in the lack of confidence index between 1978 and the spring of 1980 that is to say during the period when the bubble developed. This shows that it would be vain to explore the diamond market (or silver/gold markets) in order to find specific causes for the collapse. It was most certainly triggered by exogenous, psycho-sociological factors. (ii) In the phase between collapse and recovery (March 1980-March 1986), in contrast to what we observed with stock prices, there is no connection whatsoever between diamond price changes and the fluctuations of the lack of confidence index. Perhaps the story would be different if one could use a confidence index specially pertaining to the diamond market. 


\section{References}

(1) BERNANKE (B.S.) 1983: Non-monetary effects of the financial crisis in the propagation of the Great Depression. American Economic Review 73,257.

(2) BOUCHAUD (J.-P.), POTTERS (M.) 1997: Théorie des risques financiers. Alea-Saclay, Eyrolles. Paris.

(3) CALDARELLI (G.), MARSILI (M.), ZHANG (Y.-C.) 1997: A prototype model of stock exchange. Europhysics Letters 40,479.

(4) FARREL (M.L.) 1972: The Dow Jones averages 1885-1970. Dow Jones. Princeton.

(5) FEIGENBAUM (J.A.), FREUND (P.G.O.) 1996: Discrete scaling in stock markets before crashes. International Journal of Modern Physics B 10,3737.

(6) HARRISON (F.) 1983: The power in the land. An inquiry into unemployment, the profits crisis and land speculation. Shepheard-Walwyn. London.

(7) LUX (T.), MARCHESI (M.) 1999: Scaling and criticality in a stochastic multi-agent model of a financial market. Nature 397, 498.

(8) MACAULAY (F.R.) 1938: The movements of interest rates, bond yields and stock prices in the United States since 1856. National Bureau of Economic Research. New York.

(9) MANTEGNA (R.N.), STANLEY (H.E.) 1997: Stock market dynamics and turbulence: parallel analysis of fluctuation phenomena. Physica A 239,255.

(10) MANTEGNA (R.N.), STANLEY (H.E.) 1999: Scaling approach in finance. Cambridge University Press. Cambridge (in press).

(11) MISHKIN (F.S.) 1991: Asymmetric information and financial crises: a historical perspective. in: Hubbard (R.G.): Financial markets and financial crises. National Bureau of Economic Research. University of Chicago Press. Chicago.

(12) OLIVEIRA (S.M. de), OLIVEIRA (P.M.C. de), STAUFFER (D.) 1999: Evolution, money, wars and computers. Teubner. Stuttgart. See especially chapter 4 about stock market models.

(13) OWENS (R.N.), HARDY (C.O.) 1929: Interest rates and stock speculation. A study of the influence of the money market on the stock market. George Allen and Unwin. London.

(14) ROEHNER (B.M.) 1999: Spatial analysis of real estate price bubbles: Paris, 1984-1993. Regional Science and Urban Economics 29,73.

(15) SORNETTE (D.), JOHANSEN (A.) 1997: Large financial crashes. Physica A 245,411.

(16) STAUFFER (D.), OLIVEIRA (P.M.C.), BERNARDES (A.T.) 1999: Monte Carlo simulation of volatility correlation in microscopic market model. International Journal for Theoretical and Applied Finance 2,83.

(17) WILSON (J.), SYLLA (R.), JONES (C.P.) 1990: Financial market volatility. Panics under the national banking system before 1914. Volatility in the long-run 1830-1988. in White (E.N.) Crashes and panics: the lessons from history. Dow Jones-Irwin. Homewood.

(18) WYCKOFF (P.) 1972: Wall Street and the stock markets. A chronology (1644-1971). Chillon Book Company. Philadelphia. 
Figure captions

Fig.1a Stock prices versus interest rate spread: 19th century crashes. Thick solid line: stock price index on the NYSE normalized to 100 at its peak value (left-hand vertical scale); thick dashed line: interest rate spread (right-hand vertical scale). The thin dashed line represents the interest rate for high grade commercial paper; it serves as a control variable in order to determine whether it is the spread or the interest rate which is the pivotal variable. For the purpose of facilitating comparison the left-hand vertical scale is the same for all graphs: this allows a visual comparison of the crashes' severity. The right-hand vertical scales although not identical are nevertheless comparable in the sense that their overall ranges $y_{\mathrm{max}} / y_{\min }$ are the same. The horizontal scales represent the number of months after the crash; these scales are the same for all graphs. The numbers under the title are the correlations price/spread and price/interest rate respectively. Sources: see text.

Fig.1b Stock prices versus interest rate spread: 20th century crashes. The caption is the same as for Fig.1a; note however that for the 1929 chart the scales for the stock prices (right-hand vertical scale), for the spread (left-hand vertical scale) and for time (horizontal scale) are not the same as for the other charts. This clearly shows the exceptional magnitude of the crash of 1929. Sources: see text.

Fig.2 Comparison between the spread variable and the consumer lack of confidence index before the crash of October 1987. Changes in the spread variable (solid line) and in the lack of confidence index (broken line) are fairly parallel but the first variable is much more sensitive. The lack of confidence index is the inverse of the standard confidence index obtained from surveys. Sources: Mishkin (1991), Gems and Gemology 24,140 (Fall 1998).

Fig.3 Comparison of the price of diamonds before the collapse of January 1980 with the evolution of the lack of confidence index. In the months before the market collapse the lack of confidence increased rapidly. However after the crash the lack of confidence index does not show the same pattern that we observed in Fig.1. The outcome would perhaps be different if we could use a confidence index focused on the diamond market. Sources: Gems and Gemology 24 (Fall 1998). 